Int. J. Electrochem. Sci., 13 (2018) 1931 - 1944

International Journal of

ELECTROCHEMICAL

SCIENCE

www.electrochemsci.org

\title{
Development of $\operatorname{Poly}(3,4-$ ethylenedioxythiophene(PEDOT)/carbon Nanotube Electrodes for Electrochemical Detection of Mancozeb in Water
}

\author{
Roy Zamora ${ }^{1, *}$, Federico Masis-Meléndez ${ }^{2}$, Hayden Phillips ${ }^{3}$, Luis A. Alvarado-Marchena ${ }^{4}$, \\ Ricardo Starbird ${ }^{1}$ \\ ${ }^{1}$ School of Chemistry, Costa Rica Institute of Technology, Cartago, Costa Rica \\ ${ }^{2}$ Research Center and Chemical and Microbiological Services CEQIATEC, Costa Rica Institute of \\ Technology, Cartago, Costa Rica \\ ${ }^{3}$ School of Electronic Engineering, Costa Rica Institute of Technology, Cartago, Costa Rica \\ ${ }^{4}$ Electron Microscopy Laboratory, Costa Rica Institute of Technology, Cartago, Costa Rica \\ *E-mail: rzamorasequeira@ina.ac.cr
}

doi: $10.20964 / 2018.02 .20$

Received: 25 August 2017 / Accepted: 28 September 2017 / Published: 28 December 2017

\begin{abstract}
Assessments of the risk of water contamination caused by pesticides in agricultural areas are typically conducted using laborious methods and expensive instruments. Severe chronic diseases have been connected to the presence of Mancozeb (MCZ) in several bodies of water. Consequently, it is necessary to have new tools to access MCZ residues in drinking water. The purpose of this work is to develop a novel and economical electrode to detect and quantify MCZ in water using electrochemical techniques. Electrodes coated with poly(3,4-ethylenedioxythiophene) (PEDOT) and MWCNTs were characterized using transmission electron microscopy (TEM), profilometry and Raman techniques. Cyclic voltammetry was used to characterize and quantify MCZ in solution. The electrochemical behavior of the modified electrodes was studied to obtain specific signals due to MZC and MWCNT interaction. The results confirmed that this approach is a sensitive and selective electroanalytical method for determining MCZ with a working linear range of $25-150 \mu \mathrm{M}$ and a limit of detection set at $10 \mu \mathrm{M}$. The advantages of this PEDOT/MWCNT electrode coat include quick and feasible detection of pesticides in drinking water as well as a new approach for sensing analysis in monitoring programs and research studies.
\end{abstract}

Keywords: Mancozeb, Nanotubes, Electrode, Cyclic voltammetry, Conductive polymers 
(C) 2018 The Authors. Published by ESG (www.electrochemsci.org). This article is an open access article distributed under the terms and conditions of the Creative Commons Attribution license (http://creativecommons.org/licenses/by/4.0/). 